\title{
A Histopathological Study Reveals New Insights Into Responses of Chestnut (Castanea spp.) to Root Infection by Phytophthora cinnamomi
}

\author{
Patrícia Fernandes, ${ }^{1,2}$ Helena Machado, ${ }^{1}$ Maria do Céu Silva, $3,4, \dagger$ and Rita Lourenço Costa ${ }^{1,5, \dagger}$ \\ ${ }^{1}$ Instituto Nacional de Investigação Agrária e Veterinária I.P., Quinta do Marquês, Oeiras 2780-157, Portugal \\ ${ }^{2}$ Instituto de Tecnologia Química e Biológica António Xavier (Green-it Unit), Universidade Nova de Lisboa, Oeiras, Portugal \\ ${ }^{3}$ Centro de Investigação das Ferrugens do Cafeeiro, Instituto Superior de Agronomia, Universidade de Lisboa, Oeiras 2784-505, Portugal \\ ${ }^{4}$ Linking Landscape, Environment, Agriculture and Food, Instituto Superior de Agronomia, Universidade de Lisboa, Lisboa 1349-017, Portugal \\ ${ }^{5}$ Centro de Estudos Florestais, Instituto Superior de Agronomia, Universidade de Lisboa, Lisboa 1349-017, Portugal \\ Accepted for publication 2 August 2020.
}

\begin{abstract}
The European chestnut (Castanea sativa) is threatened by the hemibiotrophic oomycete Phytophthora cinnamomi, the causal agent of ink disease. Chestnut species have different susceptibility levels to P. cinnamomi, with the Asian species (C. crenata; $C$. mollissima) exhibiting the highest level of resistance. A histological approach was used to study the responses exhibited by susceptible and resistant chestnut genotypes by characterizing the early stages of $P$. cinnamomi infection and the cellular responses it induces in roots. C. sativa (susceptible) and C. crenata (resistant) plantlets were inoculated with a $P$. cinnamomi virulent isolate with a zoospore suspension or by direct contact with mycelia agar pieces. Root samples were collected at $0.5,3.5,24,48$, and $72 \mathrm{~h}$ after inoculation (hai) for microscopic observations. Penetration was observed in both species at 0.5 and 3.5 hai with mycelium and zoospore inoculations, respectively. In both inoculation
\end{abstract}

ABSTRACT methods, following penetration into the rhizodermis, P. cinnamomi hyphae grew inter- and intracellularly through the cortex and into the vascular cylinder. $C$. crenata cells displayed a delay in the pattern of infection by having fewer cell layers colonized compared with C. sativa. At 72 hai, the collapse of the first layers of $C$. sativa cortical cells was observed, indicating the beginning of necrotrophy. $C$. crenata was able to respond more efficiently to $P$. cinnamomi than $C$. sativa by restricting the pathogen's growth area through the early activation of resistance responses such as callose deposition around some intracellular hyphae, hypersensitive response-like cell death, cell wall thickening, and accumulation of phenolic-like compounds.

Keywords: disease control, genetics, ink disease, microscopy, pest management, resistance, root rot, susceptibility
Phytophthora cinnamomi Rands, the soilborne oomycete that causes ink disease (also known as root rot), is present in several ecosystems and has reduced the native biodiversity in many forests around the globe (Hardham and Blackman 2018). Indeed, the magnitude of the ecological, scientific, and economic impacts caused by $P$. cinnamomi is recognized worldwide, as $P$. cinnamomi has been ranked in the top 10 oomycete plant pathogens (Kamoun et al. 2015). Unlike other tree pathogens, P. cinnamomi is a generalist pathogen that develops a vast range of symptoms. Plant species with less immediately evident symptoms are difficult to diagnose, creating special challenges for those trying to understand, assess, and manage the disease caused by P. cinnamomi (Sena et al. 2018).

In Portugal, one of the most affected species is the European chestnut (Castanea sativa Mill.), a multipurpose tree with economic (timber and fruit production) and ecological importance in the mountain areas of southwest Europe. P. cinnamomi has been mainly responsible for the decline in chestnut production in Portugal by 52,725 tons since 1961 (Food and Agriculture Organization of the United Nations 2019). Efforts have been made to increase the chestnut population. From 1995 to 2002, the number of chestnuts in

${ }^{\dagger}$ Corresponding authors: M. C. Silva; mariaceusilva@isa.ulisboa.pt, and R. L. Costa; rita.lcosta@iniav.pt

Funding: This research was funded by Fundação para a Ciência e a Tecnologia (FCT), Portugal, through research units UIDB/00239/2020 (CEF) and UID/AGR/ $04129 / 2020$ (LEAF), and grant SFRH/BD/115424/2016 to Patrícia Morais Fernandes. This research was done under the scope of project 414103 FCT-LxFEDER-28760, and benefited from projects PRODER 53593-"InovCast" and ALT20-03-0246-FEDER-000011-NEW Cast Rootstocks.

The author(s) declare no conflict of interest.

(C) 2021 The American Phytopathological Society a northern region of Portugal with a high incidence of $P$. cinnamomi increased $18.5 \%$, owing to newly established plantations. However, this increase was not able to offset the loss caused by P. cinnamomi (Martins et al. 2007). Currently, this pathogen is the main biological constraint to chestnut production not only in Portugal but also in several European countries (Vannini and Vettraino 2001).

Chestnuts have different susceptibility levels to $P$. cinnamomi, with the Asian species ( $C$. crenata Siebold \& Zucc.; C. mollissima Blume) exhibiting the highest level of resistance (Crandall et al. 1945). Therefore, since the last century, these species have been used as donors of resistance to P. cinnamomi in several breeding programs in Europe. It has long been recognized that a deep understanding of pathogen biology, host-pathogen interactions, and resistance mechanisms is of key importance to improve the efficiency of the breeding process. Transcriptomic and genomic studies have provided the first genetic insights into mechanisms underlying susceptible and resistant chestnut species responses to P. cinnamomi (Santos et al. 2015b, 2017a, b; Serrazina et al. 2015). Santos et al. (2017a) proposed a molecular mechanism involving several layers of defense, which includes hypersensitive response (HR)-like cell death. The authors report the upregulation of a set of genes (e.g., Cast_Gnk2-like and Calcium-dependent protein kinase) after P. cinnamomi infection, which may trigger HR-like cell death in $C$. crenata cells. Structural barriers, like active reinforcement of cell walls, are also suggested to have an important role in chestnut's defense against $P$. cinnamomi (Santos et al. 2017a). Despite this body of knowledge, advances in chestnut's molecular response to $P$. cinnamomi still need validation at the cytological level and, to date, only cell colonization and cortical parenchyma disruption have been described in $C$. sativa cells after inoculation with the pathogen (Maia et al. 2012).

Histopathology provides deeper insights into $P$. cinnamomi infection in several other hosts such as Persea americana (Phillips 
1987; van den Berg et al. 2018), Vaccinium spp. (Milholland 1975), Eucalyptus spp., Acacia spp., Xanthorrhoea australis (Cahill et al. 1989), and Quercus spp. (Blaschke 1994; Redondo et al. 2015; Ruiz Gómez et al. 2015). All of the reported interactions with this pathogen have distinct disease patterns revealing how unpredictable the $P$. cinnamomi infection process can be depending on its host. Thus, the goal of this research was to characterize the P. cinnamomi pre- and postpenetration infection stages and histological changes in the root tissues of susceptible and resistant chestnut species.

\section{MATERIALS AND METHODS}

Plants and pathogen. $C$. crenata and $C$. sativa plants were used for the histological assessment. These genotypes were provided by the TRAGSA Nursery (TRAGSA-SEPI, Maceda, Spain) and maintained by in vitro micropropagation. Shoots were multiplied and rooted according to the protocol described in Santos et al. (2017a) with the benzyladenine concentration adjusted to $0.1 \mathrm{mg} /$ liter and the addition of $100 \mathrm{mg}$ of ascorbic acid/liter to the multiplication medium. Rooted plants were transferred to containers with a vermiculite/perlite $(1: 1)$ mixture for acclimatization in a controlled cabinet at $25 \pm 1{ }^{\circ} \mathrm{C}$ with $50 \%$ relative humidity for about 7 months. During this period, plants were fertilized every 2 weeks with a Murashige and Skoog basal salt and vitamin mixture.

An isolate of $P$. cinnamomi (IMI 340340), described as the most virulent within a set of several tested isolates (Abreu et al. 1999), was used. $C$. crenata and $C$. sativa are resistant and susceptible to this P. cinnamomi isolate, as previously referred by Santos et al. (2017a), who showed that these species have a 83 and $0 \%$ survival rate, respectively.

Inoculations. Before all inoculations, the root systems of $C$. crenata and $C$. sativa were carefully washed with water to remove perlite and vermiculite. Two inoculation methods were performed (adapted from Redondo et al. 2015): (i) immersion into a soil extract zoospore suspension and (ii) direct contact with agar pieces colonized with mycelium.

$P$. cinnamomi mycelium was cultured in vegetable juice (V8) agar [20\% (vol/vol) with $3 \mathrm{~g}$ of $\mathrm{CaCO}_{3} /$ liter and $6 \mathrm{~g}$ of agar/liter] in

\section{A Inoculation with a zoospore suspension}

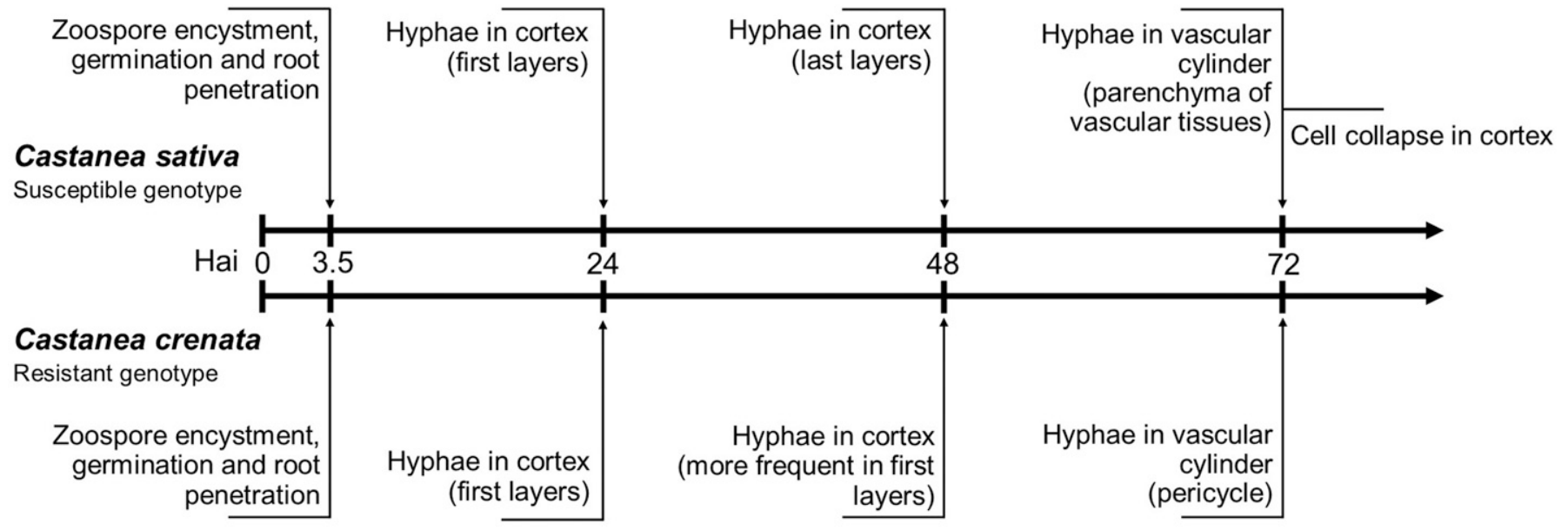

\section{B Inoculation with mycelium}

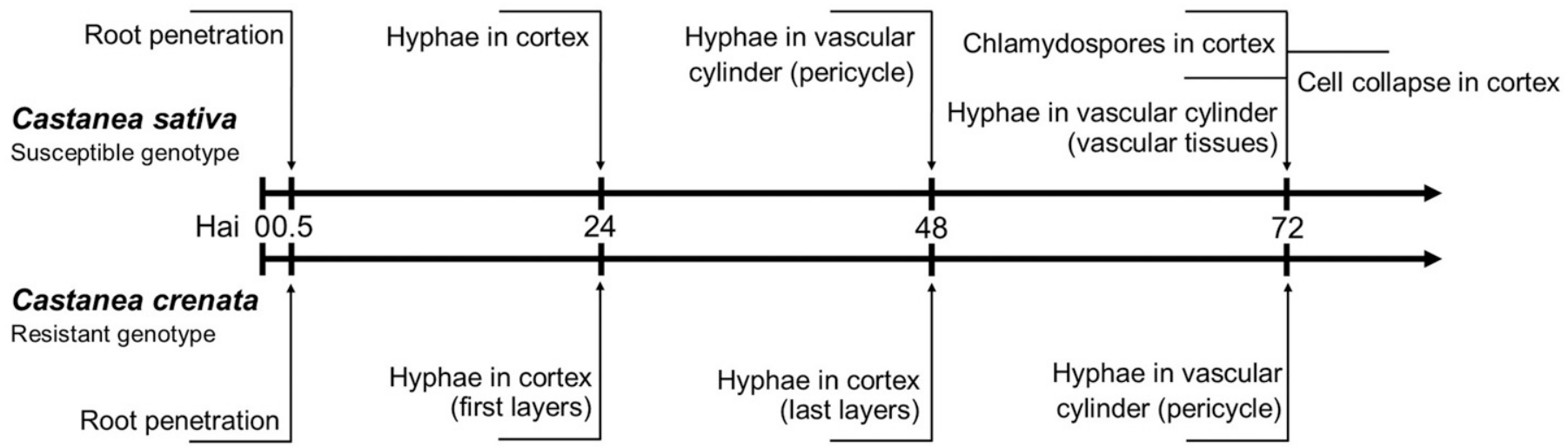

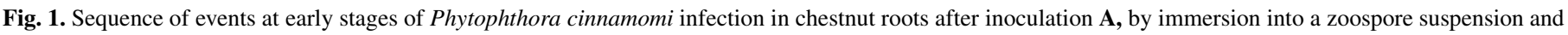

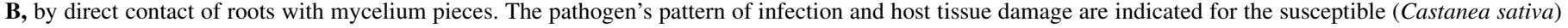
and the resistant $(C$. crenata) chestnut species in the lines above and below, respectively. Hai $=$ hours after inoculation. 
darkness at $24^{\circ} \mathrm{C}$ for 5 days. For zoospore production, soil leachate was prepared by mixing $10 \mathrm{~g}$ of soil in 1 liter of water on a magnetic stirrer for $2 \mathrm{~h}$ and left to settle for $24 \mathrm{~h}$. The leachate was filtered three times (first with a sieve small enough to filter most dirt, and twice with Whatman grade 1 filter paper) to avoid dirt on histological samples. For sporangia production, the leachate was inoculated for 3 days at $24^{\circ} \mathrm{C}$ in the dark with plugs $(1 \mathrm{~cm}$ in diameter) of $P$. cinnamomi mycelium. The cultures were placed in a
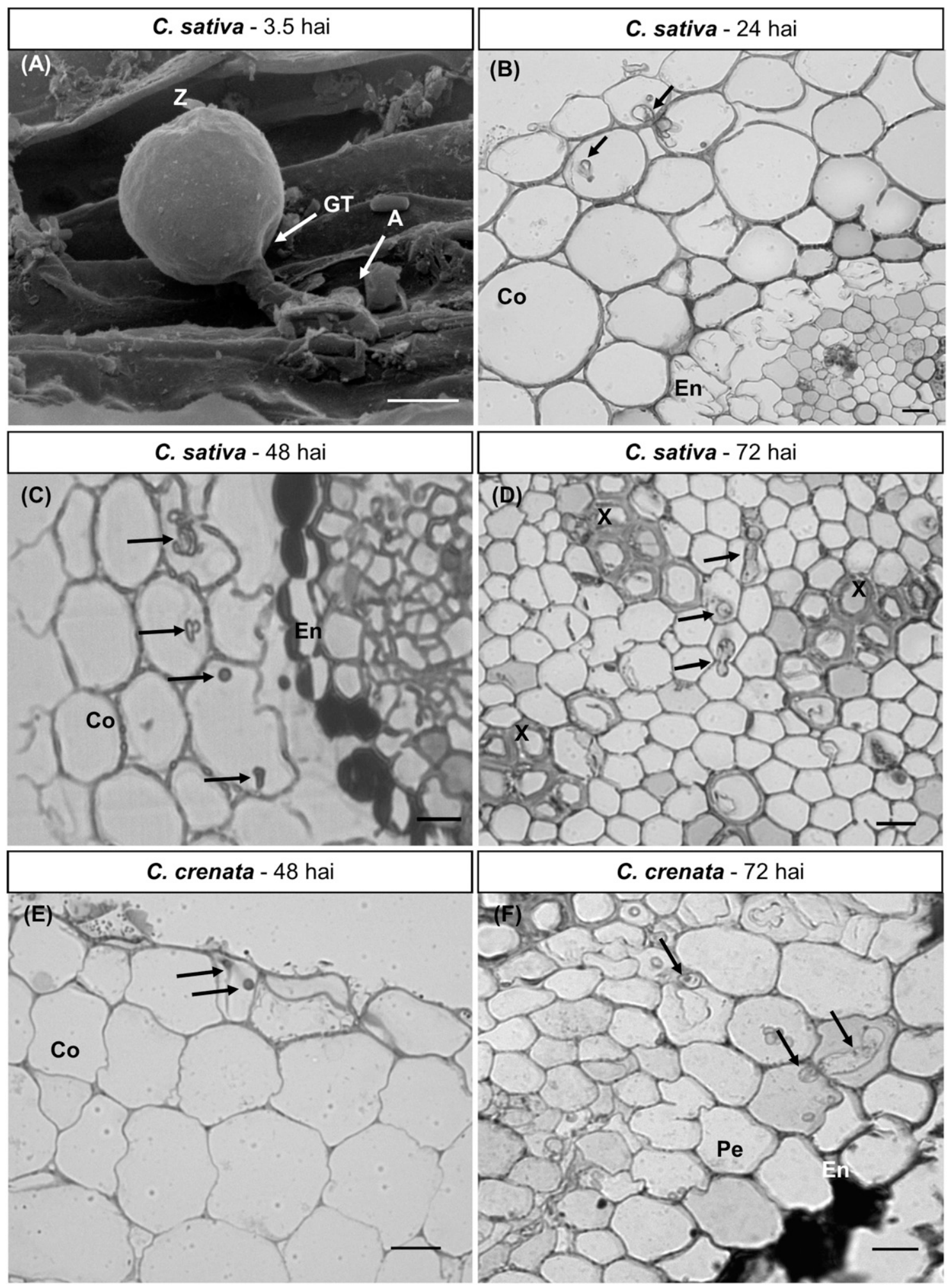

Fig. 2. Phytophthora cinnamomi pattern of infection in Castanea sativa and C. crenata roots after inoculation by immersion into a zoospore suspension. A, Scanning electron microscopy image showing encysted zoospores and the emerging germ tube growing across the root surface (arrows) of $C$. sativa until the development of an appressorium-like swelling that allows the pathogen to penetrate at $3.5 \mathrm{~h}$ after inoculation (hai). Light microscope observations of cross-sections stained with toluidine blue are as follows. B, Hyphae (arrows) colonizing the first layers of the cortex in C. sativa roots at 24 hai. C, Hyphae (arrows) colonizing the last layers of the cortex next to the endodermis at 48 hai in C. sativa roots. D, Hyphae (arrows) colonizing the parenchymal cells of the vascular tissues, next to the xylem vessels at 72 hai in $C$. sativa roots. E, Hyphae (arrows) colonizing the first layers of the cortex at 48 hai in $C$. crenata roots. F, Hyphae colonizing the pericycle cells 72 hai in C. crenata roots. Bars $=5 \mu \mathrm{m}$ in A and $10 \mu \mathrm{m}$ in B, C, D, E, and F. Z = zoospore, GT = germ tube, $\mathrm{A}=$ appressorium-like swelling, Co $=$ cortex, $\mathrm{En}=$ endodermis, $\mathrm{X}=$ xylem vessel, and $\mathrm{Pe}=$ pericycle cell . 
cold chamber at $4^{\circ} \mathrm{C}$ for 30 min to induce zoospore release, which occurred approximately $1 \mathrm{~h}$ after the temperature shock. After this period, the suspension was filtered with gauze to remove the mycelium plugs. The zoospore concentration was determined with a hemocytometer and adjusted to approximately 10,000 zoospores/ $\mathrm{ml}$ by adding soil extract solution. The plants were inoculated individually by immersion in $40 \mathrm{ml}$ of inoculum. For noninfected controls, roots were inoculated with the soil extract suspension. For the second inoculation method, several pieces of actively growing mycelium were placed covering the root system. To avoid desiccation, plants were placed in individual humid chambers with a paper base and a cotton ball moistened with sterile distilled water. The roots next to the collar were forced upward as a result of their interaction with the paper base. For this reason, only approximately $80 \%$ of the root system was inoculated because the physical restrictions did not allow inoculation in the roots next to the collar. Noninfected controls were kept in the same conditions. All inoculations were maintained at $24^{\circ} \mathrm{C}$.

Sampling and light microscopy observations. Root segments 2 to $5 \mathrm{~mm}$ in length and 0.5 to $1 \mathrm{~mm}$ in diameter were sampled from the root systems at $0.5,3.5,24,48$, and $72 \mathrm{~h}$ after inoculation (hai). At each time point, root samples were collected from different plants per treatment.

To visualize the progression of $P$. cinnamomi infection and host responses under bright-field and fluorescence microscopy, root samples were fixed following a technique adapted from Redondo et al. (2015). Root segments were immersed in formaldehyde (37 to $38 \%$ )/glacial acetic acid/ethanol $(70 \%)$ in a 1:1:18 proportion for a minimum period of $24 \mathrm{~h}$. Before sectioning, samples were rehydrated with distilled water for $15 \mathrm{~min}$. Sectioning (20 to $25 \mu \mathrm{m}$ thick) was performed using a freezing microtome (Leica CM1850; Leica, Zurich, Switzerland).

To analyze $P$. cinnamomi postpenetration stages, cross and longitudinal root sections were stained and mounted in cotton blue lactophenol (Silva et al. 2002) or immersed in $0.3 \%$ diethanol (vol/ vol), prepared in $70 \mathrm{mM}$ of phosphate solution $\left(\mathrm{K}_{2} \mathrm{HPO}_{4}\right)$, $\mathrm{pH} 8.9$,

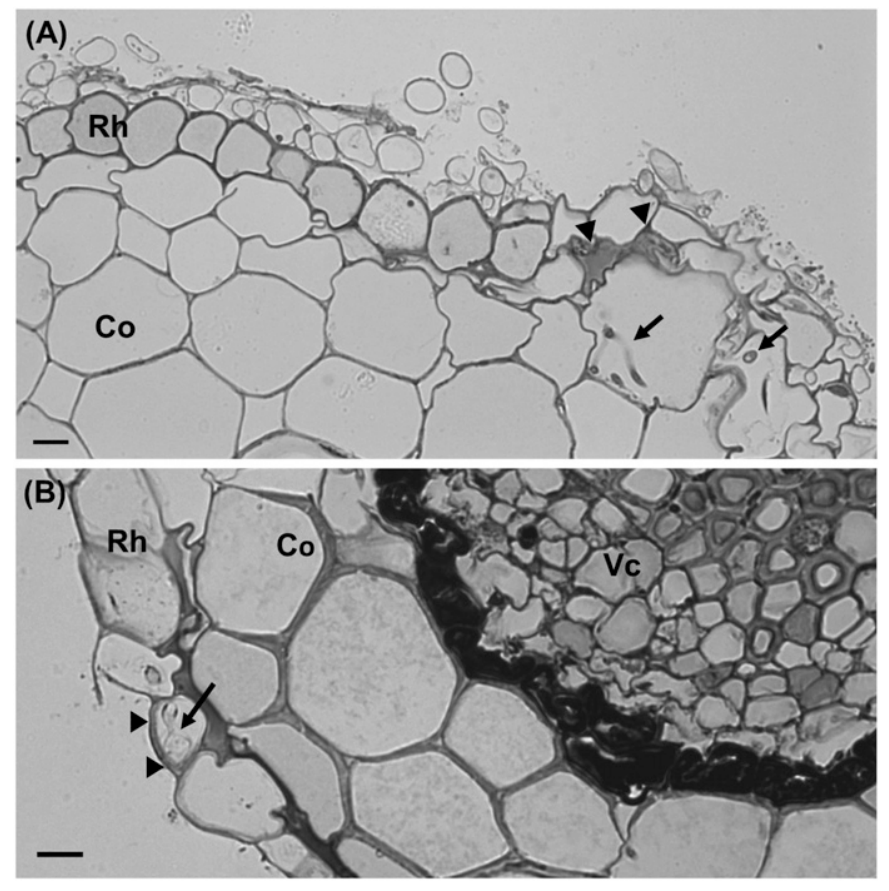

Fig. 3. Light microscopy, toluidine blue staining. Cross-sections of chestnut roots at $72 \mathrm{~h}$ after inoculation (hai) with a zoospore suspension of Phytophthora cinnamomi. A, Hyphae (arrows) colonizing the first layers of the cortex causing cellular collapses (triangles) in Castanea sativa roots. Note the altered cell walls in the infected area. B, Wall thickening (triangles) of a C. crenata rhizodermal cell infected by an intracellular hypha (arrow). Bars $=10 \mu \mathrm{m} . \mathrm{Rh}=$ rhizodermis, $\mathrm{Co}=$ cortex , and $\mathrm{Vc}=$ vascular cylinder. for 4 min, washed in distilled water, and mounted in $70 \%$ glycerol (vol/vol) (Talhinhas et al. 2011).

To detect autofluorescent cells, longitudinal sections of root tissue were placed in $0.07 \mathrm{M}$ of phosphate solution, $\mathrm{pH} 8.9$, for $5 \mathrm{~min}$ and mounted in the same solution (Diniz et al. 2012; Silva et al. 2002). Autofluorescence under blue light epifluorescence indicates the presence of phenolic-like compounds and cytoplasmatic autofluorescence and/or browning is frequently associated with host cell death (Bennett et al. 1996; Heath 1998). Autofluorescence can also be an indicator of fungal death (Heath 1984).

Callose deposition was identified as bright-yellow fluorescent deposits. Longitudinal sections of infected roots were placed in $0.07 \mathrm{M}$ of phosphate solution, $\mathrm{pH} 8.9$, for $10 \mathrm{~min}$ and then transferred to $0.01 \%$ (wt/vol) aniline blue in phosphate solution for another $10 \mathrm{~min}$. Sections were mounted in the same aniline blue solution and observed using ultraviolet light (Mellersh and Heath 2003; Silva et al. 2002).

To detect lignin, longitudinal sections of infected roots were prewashed in ethanol (96\%) and placed in phloroglucinol- $\mathrm{HCl}$ reagent (Jensen 1962) for $5 \mathrm{~min}$ and mounted in $70 \%$ glycerol. The red color indicated the presence of lignin (Pomar et al. 2002).

Viability of cells was tested on longitudinal sections of infected root fragments immersed in Evans blue (0.5\%, wt/vol) for $15 \mathrm{~min}$, after which they were rinsed and mounted in distilled water. Dead or damaged cells are unable to exclude Evans blue and thus stain deep blue (Loureiro et al. 2012).

To optimize the observation of pathogen structures and host responses, small root sections ( 2 to $3 \mathrm{~mm}$ long) were fixed for $2 \mathrm{~h}$ in a $3 \%(\mathrm{vol} / \mathrm{vol})$ glutaraldehyde solution made in $0.1 \mathrm{M}$ of sodium cacodylate buffer at $\mathrm{pH}$ 7.1. After this step, tissues were washed in sodium cacodylate buffer $(3 \times 20 \mathrm{~min})$ and postfixed for $2 \mathrm{~h}$ with $1 \%$ osmium tetroxide in the same buffer. Tissues were dehydrated using a graded ethanol series (10 to $90 \%$ in $10 \%$ increments) for $15 \mathrm{~min}$ each and two times at $100 \%$ ethanol for $30 \mathrm{~min}$. After dehydration, tissues were embedded in Spurr's resin (Sigma-Aldrich) and polymerized overnight at $70^{\circ} \mathrm{C}$ (adapted from Silva et al. 2002). Because it was difficult to impregnate chestnut roots with resin, small changes to the described technique were introduced. The dehydration periods in ethanol were increased ( 80 and $90 \%$ for $1 \mathrm{~h}$ each; rinsed twice with $100 \%$ ethanol for $1 \mathrm{~h}$ each) and steps in the Spurr's resin embedding were added to make it more gradual (proportion resin/ethanol: 1:3, 1: $2,1: 1,2: 1$, and $3: 1$ for $24 \mathrm{~h}$ each; and $100 \%$ resin changes every $24 \mathrm{~h}$ for 1 week), performed at $8^{\circ} \mathrm{C}$ and with agitation (approximately $10 \mathrm{rpm})$. Semithin sections $(2 \mu \mathrm{m})$ were stained with $0.5 \%$ toluidine blue solution and observed with light microscopy.

All observations were performed using light microscopes (LeitzDialux 20 and Leica DM-2500) equipped with a HB 100-W mercury bulb, UV light (excitation filter BP 340-380; barrier filter LP 430), and blue light (excitation filter BP 450-490; barrier filter LP 515).

Scanning electron microscopy. Scanning electron microscopy was used to detect zoospores at the root surface. The protocol described by Talhinhas et al. (2011) was followed with some modifications. Small fragments of root sections collected at 3.5 hai were fixed in a $3 \%$ ( $\mathrm{vol} / \mathrm{vol}$ ) glutaraldehyde solution in $0.1 \mathrm{M}$ of sodium cacodylate buffer, $\mathrm{pH} 7.1$, at $4^{\circ} \mathrm{C}$ for $2 \mathrm{~h}$. The tissues were then fixed in a mixture with equal parts of glutaraldehyde with $3 \%$ osmium tetroxide in the above buffer for $2 \mathrm{~h}$ in the dark. They were then washed three times $(10 \mathrm{~min}$ each) in $0.1 \mathrm{M}$ of sodium cacodylate buffer, $\mathrm{pH} 7.1$, and postfixed for $2 \mathrm{~h}$ in the dark in $3 \%$ osmium tetroxide in the above buffer. The tissues were rinsed with the same buffer $(3 \times 10 \mathrm{~min})$ followed by distilled water $(3 \times$ $10 \mathrm{~min}$ ). After the washing steps, the root segments were dehydrated in a graded ethanol series $(10,20,30,50,70,90$, and $100 \%)$ for 10 min each (twice for $100 \%$ ), once with a mixture $(1: 1)$ of $100 \%$ ethanol and $100 \%$ acetone for 10 min, and kept in 100\% acetone. Samples were dried in a critical-point dryer, mounted on aluminum stubs, coated with gold-palladium, and examined using a scanning electron microscope (JEOL JSM-5200LV) at $20 \mathrm{kV}$. 
Image capture and processing. Pictures from sections were taken with a Leica DFC340FX camera and processed using Leica Application Suite software (version 4.12; Leica Microsystems).

For each sampling time point of the mycelium inoculation, a random set of root-infected sections was chosen for measurement of the percentage of infected area, which was the ratio between the area of infected root tissues and the total area present in the image. For each time point, a minimum of 10 measurements were performed.

Statistical analysis. For statistical analysis of data concerning pathogen growth (measured as the percentage of infected area), the
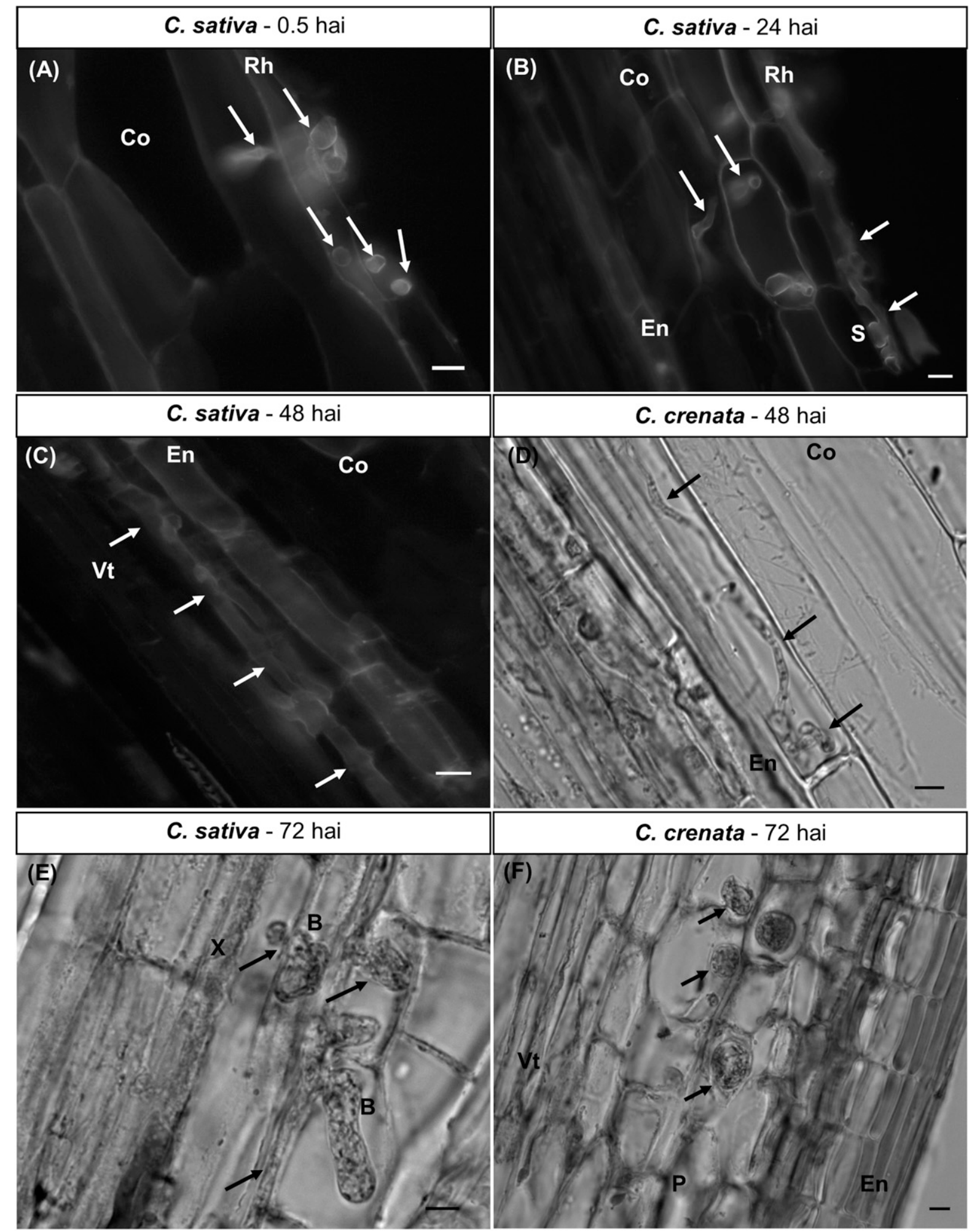

Fig. 4. Light microscopy. Phytophthora cinnamomi pattern of infection in Castanea sativa and C. crenata roots after inoculation by direct contact with mycelium pieces. Longitudinal sections with $\mathbf{A}, \mathbf{B}$, and $\mathbf{C}$, diethanol staining and $\mathbf{D}, \mathbf{E}$, and F, cotton blue staining. A, Several hyphae (arrows) penetrating the rhizodermis $0.5 \mathrm{~h}$ after inoculation (hai). B, Hyphae (arrows) colonizing the cortex cells 24 hai. At this time point, it was possible to identify swellings, which occurred in both species. C, Hyphae (arrows) colonizing the pericycle of C. sativa roots 48 hai. D, Hyphae (arrows) colonizing the last layers of the cortex cells, next to the endodermis in C. crenata roots 48 hai. E, Hyphae (arrows) entering the xylem vessels in C. sativa roots 72 hai. Some botryose hyphae were identified. F, Hyphae colonizing the pericycle cells in $C$. crenata roots 72 hai. Bars $=10 \mu \mathrm{m}$. Co $=$ cortex, $\mathrm{Rh}=$ rhizodermis, En $=$ endodermis, $\mathrm{S}=\mathrm{swelling}, \mathrm{Vt}=\mathrm{vascular}$ tissues, $\mathrm{X}=$ xylem vessel, $\mathrm{B}=$ botryose, and $\mathrm{P}=$ pericycle. 
$t$ test was applied using GraphPad Prism software (version 5.00 for Windows; GraphPad Software, San Diego, CA) and arcsinetransformed percentages were used.

\section{RESULTS}

Necrotic lesions were absent at 72 hai. All inoculated plants survived during the experiments. The roots did not show any macroscopic lesions such as dark necrotic lesions or rot symptoms characteristic of $P$. cinnamomi infection (Santos et al. 2015a). However, root softness and exfoliation of the external surface of more lignified roots occurred over time and was noticeable at 72 hai. Other symptoms associated with aerial parts, such as discoloration and dieback of leaves, were not detected.

$P$. cinnamomi infection progresses slower in $C$. crenata cells than in $C$. sativa. Inoculations of chestnut roots with a zoospore suspension produced a slight delay of the colonization process compared with roots inoculated by direct contact with mycelium pieces. Figure 1 summarizes the timeline of the $P$. cinnamomi infection pattern observed in $C$. sativa and C. crenata using both inoculation methods.
Zoospore encystment, germination, and rhizodermis penetration occurred within 3.5 hai in both host species. The encysted zoospores were observed at the root surface with diameters varying from 9 to $12 \mu \mathrm{m}$. The germ tube emerged and grew across the plant surface until an appressorium-like swelling developed (Fig. 2A). After root penetration, hyphae grew inter- and intracellularly, colonizing the first layers of the cortical parenchyma cells (Fig. 2B) of both species by 24 hai. In the susceptible $C$. sativa roots, hyphae colonized all cell layers of the cortical parenchyma at 48 hai (Fig. 2C) and reached the parenchyma cells of the vascular tissues (Fig. 2D) by 72 hai. From 48 hai, the pattern of $P$. cinnamomi infection was differentiated between species by displaying a slight delay in C. crenata cells. At 48 hai, some hyphae were identified in the last layers of $C$. crenata cortical parenchyma; however, the infections were more frequent in the first layers (Fig. 2E). At 72 hai, the more advanced infections were still in the first layers of the vascular cylinder, namely the pericycle (Fig. $2 \mathrm{~F}$ ). In $C$. sativa cells, it was possible to confirm the switch from biotrophy to necrotrophy, as the collapse of the first layers of the cortical cells was observed at 72 hai (Fig. 3A). At this time point, some infected rhizodermal cells in C. crenata presented thickened walls (Fig. 3B). In both chestnut
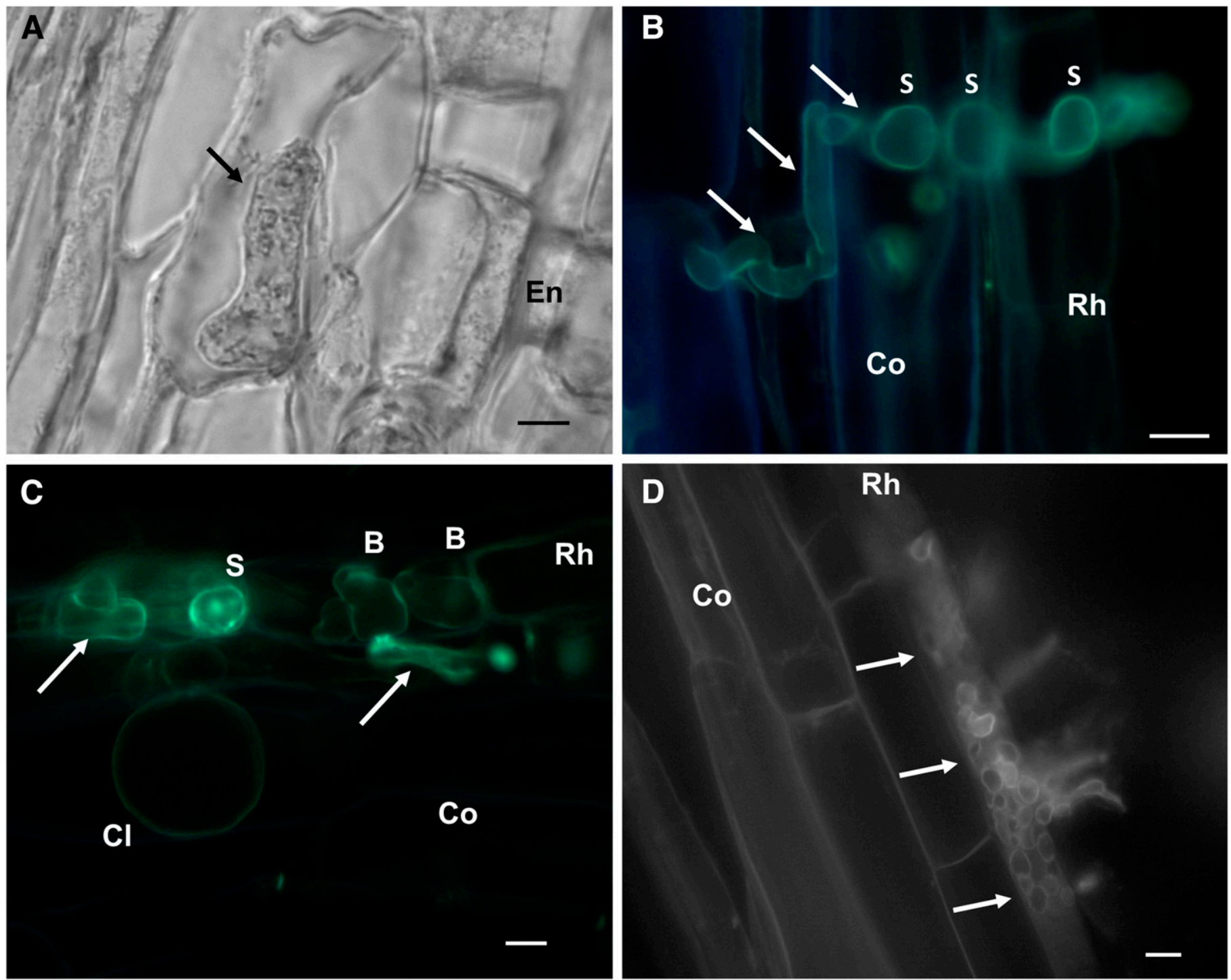

Fig. 5. Light microscopy. Identification of pathogen structures in longitudinal sections from roots inoculated by direct contact with Phytophthora cinnamomi mycelium pieces and stained with $\mathbf{A}$, cotton blue lactophenol, $\mathbf{B}$ and $\mathbf{C}$, aniline blue, and $\mathbf{D}$, diethanol. A, A botryose hypha (arrow) colonizing the vascular cylinder of Castanea crenata roots $72 \mathrm{~h}$ after inoculation (hai). B, Penetration of $C$. sativa rhizodermis and colonization of the cortical cells by hyphae (arrows) with swellings 72 hai. C, C. sativa rhizodermal and cortical cells colonized by hyphae (arrows) with swellings, botryose hyphae, and thin-wall chlamydospores (survival structure) 72 hai. D, Several hyphae penetrations and stromata (hyphae aggregations) in C. crenata rhizodermis 72 hai. Bars $=10 \mu \mathrm{m}$. En $=$ endodermis, S = swelling, $\mathrm{Co}=$ cortical parenchyma, $\mathrm{Rh}=$ rhizodermis, $\mathrm{B}=$ botryose, and $\mathrm{Cl}=$ chlamydospore . 
species, the hyphae developed in the course of the infection were thin, with little size variation (ranging from 1 to $4 \mu \mathrm{m}$ thick), and no other $P$. cinnamomi structures were identified.

In roots inoculated by direct mycelium contact, penetration into the rhizodermis occurred by 0.5 hai in both chestnut species (Fig. 4A). At 24 hai, hyphae were detected in the cortical parenchyma (Fig. 4B). These hyphae were thicker compared with those developed during the zoospore inoculation. At this time point, different hyphae were observed regarding size and structure (Fig. 5A and B). Thickness ranged from 1 to $14 \mu \mathrm{m}$, and the thickest hyphae were also irregular and often with a botryose aspect (Fig. 5A). Ramifications with swellings (vesicular-like structures) were also identified (Figs. 4B and 5B). At 24 hai, the pattern of infection started to differentiate between species. $P$. cinnamomi hyphae had colonized more layers of the cortical parenchyma in $C$. sativa cells compared with $C$. crenata. The infection reached the pericycle cells in $C$. sativa root tissues at 48 hai (Fig. $4 \mathrm{C}$ ), while $P$. cinnamomi structures in $C$. crenata were only identified in the last layers of the cortical parenchyma, next to the endodermis (Fig. 4D). By 72 hai, the hyphae reached the xylem vessels in C. sativa (Fig. 4E), and cellular collapse was also identified in the cortical parenchyma (Fig. 6), like in roots inoculated with zoospores. At this time point, hyphal growth reached the pericycle in $C$. crenata cells (Fig. 4F). At this stage of the infection process, survival structures in $C$. sativa were identified, such as thin-walled chlamydospores, which were often detected together with several hyphae, botryose hyphae, and swellings (Fig. 5C). Other identified survival structures were hyphal aggregations defined as stromata (Fig. 5D). These were identified in both species, were variable in density and appearance, and sometimes formed a network of stromata. The structures described above were not identified in tissues inoculated with the zoospore suspension. No oospores or gametangia were found.

The infection area of $P$. cinnamomi is lower in $C$. crenata cells. The inoculation with mycelium presented a higher number of infections, allowing quantification of the area of infection and statistical data analysis. The percentage of the colonized areas showed a progressive increase of $P$. cinnamomi establishment in the host tissues (Fig. 7). C. crenata showed a lower percentage of colonized areas, revealing significant differences between species at all time points except for 0.5 hai (Fig. 7).

Early induction of resistance responses in $C$. crenata during $\boldsymbol{P}$. cinnamomi infection. The first cellular changes displayed by the resistant genotype were observed at 0.5 hai and corresponded to callose deposition around some intracellular hyphae within the rhizodermal cells (Fig. 8A; Table 1). At more advanced stages of the infection, this response was occasionally detected in the rhizodermal and cortical cells. The autofluorescence of rhizodermal and cortical parenchyma cell walls was also detected at 0.5 hai (Table 1), indicating the accumulation of phenolic-like compounds. The accumulation of these compounds increased throughout the infection process, leading to the thickening of cell walls and blockage of some infection sites (Fig. 8B). In these areas, autofluorescent hyphae were also detected, indicating the death of the pathogen's structure (Fig. 8B). From 0.5 hai, $C$. crenata also showed HR (recognized by browning and/ or autofluorescence of cytoplasmic contents and by deep blue staining with Evans blue) (Fig. 8C, D, and E; Table 1). These responses were only observed at the infection areas in which $P$. cinnamomi growth was restricted to the rhizodermis and first layers of cortical cells.

As shown in Table 1, in the susceptible $C$. sativa roots, callose deposition around some intracellular hyphae of rhizodermal and cortical cells was detected from 24 hai. The accumulation of phenolic-like compounds was occasionally detected in cell walls of infected areas in the cortical parenchyma at 72 hai. Some dead hyphae were also sporadically observed.

\section{DISCUSSION}

In this work, we studied two chestnut genotypes ( $C$. sativa and C. crenata), aiming to compare the pattern of infection and to elucidate cellular mechanisms associated with susceptibility and resistance involved in chestnut $-P$. cinnamomi interaction. $P$. cinnamomi was able to colonize the root tissues of both genotypes in two different inoculation methods. Macroscopically, some alterations in root integrity were detected, which were also reported during the early stages of infection for other woody species (Cahill and McComb 1992; Ruiz Gómez et al. 2015). In the same reports, necrotic lesions were detected on the root tips within the first 24 hai. However, in this study, such lesions were not observed.

The inoculation method that best mimics nature is root immersion into a zoospore suspension. In natural conditions, the infection process usually initiates by biflagellate zoospores that are chemotactically attracted to roots (Hardham and Blackman 2018). Zoospores have to shed their flagella, encyst, and grow a germ tube across the root surface until an appressorium-like swelling develops, which allows the pathogen to penetrate through the rhizodermis (Fawke et al. 2015; Hardham 2007). However, when roots were inoculated with mycelium, the infection process initiated directly by hypha penetration on the rhizodermis anticipating the progression of the pathogen. Thus, the speed of $P$. cinnamomi infection in Castanea spp. is influenced by the method of inoculation, as reported for other species such as $Q$. ilex (Redondo

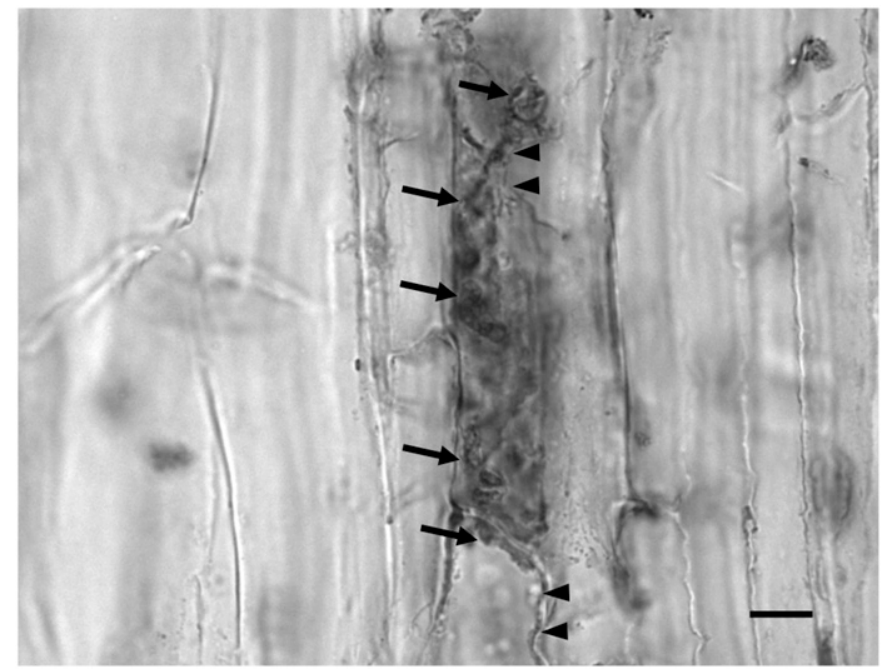

Fig. 6. Light microscopy, cotton blue lactophenol staining. Longitudinal section of Castanea sativa roots $72 \mathrm{~h}$ after inoculation (hai) by direct contact with Phytophthora cinnamomi mycelium. Hyphae (arrows) colonizing cortical parenchyma layers and causing cellular collapse. Note the altered cell walls (triangles) around the infected area. Bar $=10 \mu \mathrm{m}$.

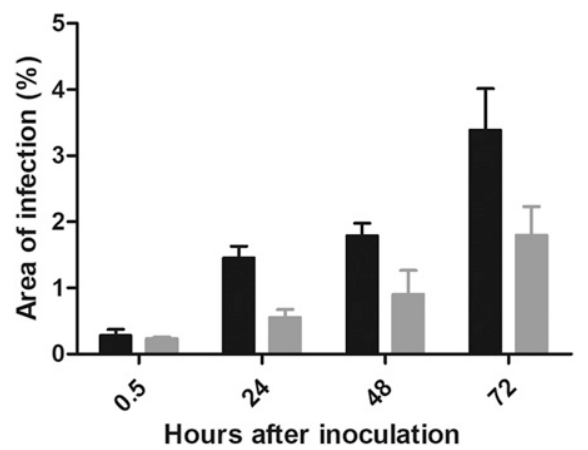

Castanea sativa Castanea crenata

Fig. 7. Percentage of area colonized by Phytophthora cinnamomi structures in Castanea sativa (susceptible) and $C$. crenata (resistant) roots inoculated by direct mycelium contact. Data were collected at $0.5,24,48$, and $72 \mathrm{~h}$ after inoculation (hai). Values did not differ in C. crenata and $C$. sativa at 0.5 hai ( $t$ test $=0.490 ; P=0.634$ ) but were significantly lower in $C$. crenata at 24 hai ( $t$ test $=4.277 ; P \leq 0.001), 48$ hai $(t$ test $=2.311 ; P=0.036)$ and 72 hai $(t$ test $=$ $2.136 ; P=0.039)$. 
et al. 2015). Nevertheless, with both inocula, $P$. cinnamomi colonized the root tissues at all time points, reached the vascular cylinder, and developed similar histological changes in Castanea cells.
In both inoculation methods, there were no differences between the susceptible and resistant chestnuts regarding the penetration stage. However, C. crenata presented a slower colonization process. $P$. cinnamomi did not reach the vascular tissues or induce cell
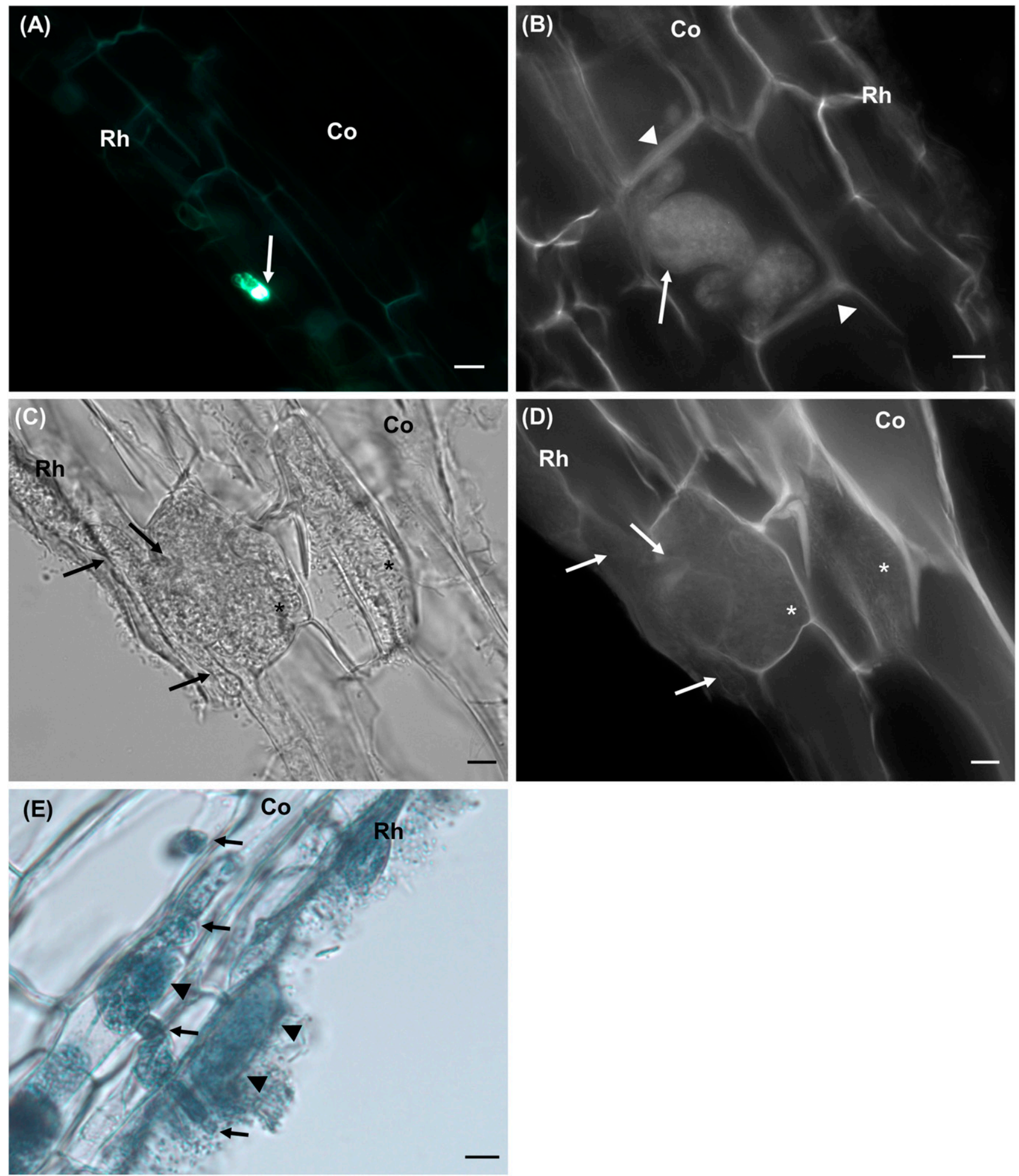

Fig. 8. Light microscopy. Longitudinal sections of Castanea crenata roots inoculated with Phytophthora cinnamomi by direct contact with mycelium pieces are as follows. A, Aniline blue fluorescence test. Callose (bright fluorescence) around an intracellular hypha (arrow) $0.5 \mathrm{~h}$ after inoculation (hai). B, Epifluorescence test using blue light. Infected area showing an autofluorescent hypha (arrow) within a cortical cell and autofluorescence of cell walls (triangles) 72 hai. C, Bright-field and $\mathbf{D}$, epifluorescence test using blue light. $\mathbf{C}$, A penetration site showing cytoplasmic content disorganization of the rhizodermal infected cell and an adjacent cortical cell. D, These cells exhibited autofluorescence of cell walls and cytoplasmic content (asterisks) at 72 hai. Autofluorescence indicates the accumulation of phenolic-like compounds and cytoplasmic autofluorescence was associated with cell death. E, Evans blue test. Infected area showing dead hyphae (arrows) and death of rhizodermal and cortical cells (triangles), indicated by deep blue staining 72 hai. Bars $=10 \mu \mathrm{m}$. Rh $=$ rhizodermis and Co $=$ cortex. 
collapse in the resistant species, contrary to what we observed in C. sativa in which the infection was already established in the vascular tissues at 72 hai and cortical cells had started to collapse, confirming the beginning of the pathogen's necrotrophic growth. This hemibiotrophic strategy of $P$. cinnamomi infection, comprising a temporary postpenetrative asymptomatic biotrophy that is succeeded by a phase of destructive necrotrophy, was also described in susceptible roots of chestnut (Maia et al. 2012) and other hosts (Crone et al. 2013; Redondo et al. 2015).

The analysis of $P$. cinnamomi infection, following the inoculation with mycelium, revealed an increase of the infection area that clearly defines the pathogen's behavior over time. P. cinnamomi was able to progressively establish in the cells of both chestnut genotypes; however, it revealed a significantly lower area of infection in C. crenata than in $C$. sativa from 24 hai.

Another difference detected between susceptible and resistant chestnuts was the development of $P$. cinnamomi survival structures in $C$. sativa roots, such as resting spores (chlamydospores) and hyphal aggregations (stromata). At the same time (72 hai), cellular collapse was detected. Indeed, the development of these survival structures is often observed when the host tissue is damaged (Jung et al. 2013; Zentmyer and Mircetich 1966). Chlamydospores and stromata are found in naturally infected stands (Crone et al. 2013), which has extreme importance for pathogen colonization and subsequent survival in host tissues. These structures were not observed in roots infected by zoospores, which might be related to the delay in the infection process. Redondo et al. (2015) also identified these structures in mycelium inoculations only, at 7 days after inoculation.

Plants rely on the innate immunity of each cell and systemic signals coming from infection sites to initiate a response mechanism (Jones and Dangl 2006). Plants can respond to oomycete infection by inducing several cellular responses, including callose deposition (around hyphae or cell walls), reorganization of the cytoskeleton and endomembrane system, aggregation of cytoplasm and formation of wall appositions in hyphae, increase of cytoplasmic $\mathrm{Ca}^{2+}$ concentration, formation of reactive oxygen species, synthesis of pathogenesis-related proteins, and HR cell death (Hardham 2007).

After inoculation with $P$. cinnamomi, $C$. crenata upregulates a set of genes that are involved in the responses described and may inhibit the pathogen's progression (Serrazina et al. 2015). Santos et al. (2017a) evaluated the expression profiles of eight candidate resistance genes to $P$. cinnamomi, suggesting the hypothesis that susceptible and resistant chestnuts share common mechanisms of response. Indeed, the results reported in the present work validate this hypothesis at the cellular level. However, C. crenata seems to respond more efficiently, as the restricted pathogen's growth was associated with a series of early responses, including HR-like cell death, accumulation of phenolic-like compounds, and callose deposition around intracellular hyphae.

The HR, a rapid localized pathogen-induced cell death, might be an efficient defense against biotrophic pathogens, which depend on living host cells for their survival (Balint-Kurti 2019). In the case of hemibiotrophs, HR may be beneficial to the host in the early stages of infection during biotrophy. However, HR is not effective if induced late in the interaction in the necrotrophic phase (BalintKurti 2019; Jupe et al. 2013; Münch et al. 2008). The HR is characterized by a rapid loss of membrane integrity in infected host cells and the accumulation of brown phenolic compound oxidation products (Heath 2000). Santos et al. (2017a) suggested that several genes upregulated after $P$. cinnamomi infection may be involved in the induction of $C$. crenata HR-like cell death. Some of these encode for antifungal proteins (Cast_Gnk2-like) and others are regulated by salicylic acid (e.g., Calcium-dependent protein kinase), which is known to trigger HR in plant cells (Brodersen et al. 2005). HR cell death has also been reported in other host-Phytophthora spp. interactions (Oßwald et al. 2014; Robinson and Cahill 2003; Vleeshouwers et al. 2000).

Structural barriers are often developed by the cross-linking of phenolic compounds. This confers a reinforced wall hardly degraded by the enzymes of the pathogen (Underwood 2012). In this study, the early accumulation of phenolic-like compounds in cell walls was observed from 0.5 hai in C. crenata root tissues, which may prevent the spread of some hyphae. The accumulation and polymerization of phenolic compounds leads to host cell wall lignification (Pomar et al. 2002). Lignin is often detected in the early stages of infection in plant- $P$. cinnamomi interactions (Cahill and McComb 1992; van den Berg et al. 2018). We did not detect this compound in the present study; nevertheless, cell wall lignification may occur at later stages of the infection process, as observed in chestnut hybrids tolerant to P. cinnamomi (P. Fernandes and M. C. Silva, unpublished data).

Callose is a component of specialized cell walls that is often abundant and ubiquitous in plant defense mechanisms (Chen and Kim 2009; Underwood 2012). In P. cinnamomi interactions, callose has been described as a key player in the resistance response, limiting the pathogen's growth by accumulating around hyphae or host cell walls and inducing cell wall reinforcement (van den Berg et al. 2018). Interestingly, some reports state that callose is not responsible for controlling $P$. cinnamomi colonization (Rookes et al. 2008), meaning that this response might vary depending on the genetic makeup of the interacting organisms and also environmental conditions. In chestnut, callose deposition around intracellular hyphae was detected early in the infection process; however, it does not seem to have an important role in the interaction, since the pathogen reached the vascular cylinder in both susceptible and resistant genotypes. Transcriptomes of $C$. sativa and $C$. crenata after $P$. cinnamomi infection (Serrazina et al. 2015) validate this result, since there is no overexpression of callose synthases, which are the enzymes responsible for callose synthesis (Chen and Kim 2009).

In conclusion, $C$. crenata was able to respond more efficiently to the $P$. cinnamomi challenge than $C$. sativa, activating early resistance responses that allowed the inhibition of several infection sites and consequently reducing the colonized area. However, further research is needed, as these early host responses were not sufficient to prevent $P$. cinnamomi from reaching the vascular cylinder. The level of collar rot has been considered the main

TABLE 1. Host responses to Phytophthora cinnamomi infection in susceptible (Castanea sativa) and resistant (C. crenata) chestnut roots at different time points after inoculation

\begin{tabular}{|c|c|c|c|c|c|c|c|c|c|c|}
\hline \multirow[b]{2}{*}{ Host response (hai) ${ }^{\mathrm{a}}$} & \multicolumn{2}{|c|}{$\begin{array}{l}\text { Callose deposition } \\
\text { around intracellular } \\
\text { hyphae }\end{array}$} & \multicolumn{2}{|c|}{ Cell death } & \multicolumn{2}{|c|}{$\begin{array}{l}\text { Autofluorescence } \\
\text { and/or browning of } \\
\text { cytoplasmic contents }\end{array}$} & \multicolumn{2}{|c|}{$\begin{array}{l}\text { Autofluorescence of } \\
\text { cell walls }\end{array}$} & \multicolumn{2}{|c|}{$\begin{array}{l}\text { Lignification } \\
\text { of cell walls }\end{array}$} \\
\hline & C. sativa & C. crenata & C. sativa & C. crenata & C. sativa & C. crenata & C. sativa & C. crenata & C. sativa & C. crenate \\
\hline 24 & + & + & - & + & - & + & - & + & - & - \\
\hline 48 & + & + & - & + & - & + & - & + & - & - \\
\hline 72 & + & + & - & + & - & + & + & + & - & - \\
\hline
\end{tabular}

${ }^{\mathrm{a}}$ hai $=$ hours after inoculation.

$\mathrm{b}$ The absence and presence of response are indicated by minus and plus signs, respectively. 
resistance indicator during $P$. cinnamomi phenotyping (MirandaFontaíña et al. 2007), as the most resistant genotypes tend to have smaller necrosis. In this way, it is possible to speculate that the collar might be a blocking area for $P$. cinnamomi infection. This will be a subject of future research.

These results expand knowledge of events associated with chestnut resistance to $P$. cinnamomi at the cellular level. We unveiled the exact time points of $P$. cinnamomi lifestyle changes, which will be valuable for future gene expression analysis to obtain a more precise view of the principles underlying chestnut resistance. The identification of genes linked with the resistance of $P$. cinnamomi will help the discovery of molecular markers for molecular assisted selection of resistant genotypes in the future. This research will also be valuable to understand other $P$. cinnamomi interactions, mainly in woody species. A detailed understanding of chestnut immune functions toward P. cinnamomi infection will underpin its improvement for production and the development of better preventive measures, namely the selection of improved plant materials from breeding programs.

\section{ACKNOWLEDGMENTS}

We thank Telmo Nunes (microscopy technician at Faculdade de Ciências da Universidade de Lisboa) for technical support given during the scanning electron microscopy observations.

\section{LITERATURE CITED}

Abreu, C., Martins, L., Cardoso, A., Borges, O., Carvalho, L., and Gouveia, E. 1999. Chestnut ink disease. An integrated approach to its control. Pages 43-53 in: NATO/Science for Stability Programme Report. C. G. Abreu, ed. University of Trás-os-Montes and Alto Douro, Vila Real, Portugal.

Balint-Kurti, P. 2019. The plant hypersensitive response: Concepts, control and consequences. Mol. Plant Pathol. 20:1163-1178.

Bennett, M., Gallagher, M., Fagg, J., Bestwick, C., Paul, T., Beale, M., and Mansfield, J. 1996. The hypersensitive reaction, membrane damage and accumulation of autofluorescent phenolics in lettuce cells challenged by Bremia lactucae. Plant J. 9:851-865.

Blaschke, H. 1994. Decline symptoms on roots of Quercus robur. Eur. J. Forest Pathol. 24:386-398.

Brodersen, P., Malinovsky, F. G., Hématy, K., Newman, M. A., and Mundy, J. 2005. The role of salicylic acid in the induction of cell death in Arabidopsis acd11. Plant Physiol. 138:1037-1045.

Cahill, D., Legge, N., Grant, B., and Weste, G. 1989. Cellular and histological changes induced by Phytophthora cinnamomi in a group of plant species ranging from fully susceptible to fully resistant. Phytopathology 79: 417-424.

Cahill, D. M., and McComb, J. A. 1992. A comparison of changes in phenylalanine ammonia-lyase activity, lignin and phenolic synthesis in the roots of Eucalyptus calophylla (field resistant) and E. marginata (susceptible) when infected with Phytophthora cinnamomi. Physiol. Mol. Plant Pathol. 40:315-332

Chen, X. Y., and Kim, J. Y. 2009. Callose synthesis in higher plants. Plant Signal. Behav. 4:489-492.

Crandall, B. S., Gravatt, G. F., and Ryan, M. M. 1945. Root disease of Castanea species and some coniferous and broadleaf nursery stocks, caused by Phytophthora cinnamomi. Phytopathology 35:162-180.

Crone, M., McComb, J. A., O’Brien, P. A., and Hardy, G. E. S. J. 2013. Survival of Phytophthora cinnamomi as oospores, stromata, and thickwalled chlamydospores in roots of symptomatic and asymptomatic annual and herbaceous perennial plant species. Fungal Biol. 117:112-123.

Diniz, I., Talhinhas, P., Azinheira, H. G., Várzea, V., Medeira, C., Maia, I., Petitot, A.-S., Nicole, M., Fernandez, D., and Silva, M. C. 2012. Cellular and molecular analyses of coffee resistance to Hemileia vastatrix and nonhost resistance to Uromyces vignae in the resistance-donor genotype HDT832/2. Eur. J. Plant Pathol. 133:141-157.

Fawke, S., Doumane, M., and Schornack, S. 2015. Oomycete interactions with plants: Infection strategies and resistance principles. Microbiol. Mol. Biol. Rev. 79:263-280.

Food and Agriculture Organization of the United Nations. 2019. FAOSTAT 2019. http://www.fao.org/faostat/en/\#data/QC

Hardham, A. R. 2007. Cell biology of plant-oomycete interactions. Cell. Microbiol. 9:31-39.

Hardham, A. R., and Blackman, L. M. 2018. Phytophthora cinnamomi. Mol. Plant Pathol. 19:260-285.
Heath, M. C. 1984. Relationship between heat-induced fungal death and plant necrosis in compatible and incompatible interactions involving the bean and cowpea rust fungi. Phytopathology 74:1370-1376.

Heath, M. C. 1998. Involvement of reactive oxygen species in the response of resistant (hypersensitive) or susceptible cowpeas to the cowpea rust fungus. New Phytol. 138:251-263.

Heath, M. C. 2000. Hypersensitive response-related death. Plant Mol. Biol. 44: 321-334

Jensen, W. A. 1962. Botanical histochemistry: Principles and practice. W. H. Freeman and Company, San Francisco, CA.

Jones, J. D. G., and Dangl, J. L. 2006. The plant immune system. Nature 444: 323-329.

Jung, T., Colquhoun, I. J., and Hardy, G. E. S. J. 2013. New insights into the survival strategy of the invasive soilborne pathogen Phytophthora cinnamomi in different natural ecosystems in Western Australia. For. Pathol. 43: 266-288.

Jupe, J., Stam, R., Howden, A. J., Morris, J. A., Zhang, R., Hedley, P. E., and Huitema, E. 2013. Phytophthora capsici-tomato interaction features dramatic shifts in gene expression associated with a hemi-biotrophic lifestyle. Genome Biol. 14:R63.

Kamoun, S., Furzer, O., Jones, J. D. G., Judelson, H. S., Ali, G. S., Dalio, R. J. D., Roy, S. G., Schena, L., Zambounis, A., Panabières, F., Cahill, D., Ruocco, M., Figueiredo, A., Chen, X. R., Hulvey, J., Stam, R., Lamour, K., Gijzen, M., Tyler, B. M., Grünwald, N. J., Mukhtar, M. S., Tomé, D. F. A., Tör, M., Van Den Ackerveken, G., McDowell, J., Daayf, F., Fry, W. E., Lindqvist-Kreuze, H., Meijer, H. J. G., Petre, B., Ristaino, J., Yoshida, K., Birch, P. R. J., and Govers, F. 2015. The top 10 oomycete pathogens in molecular plant pathology. Mol. Plant Pathol. 16:413-434.

Loureiro, A., Nicole, M. R., Várzea, V., Moncada, P., Bertrand, B., and Silva, M. C. 2012. Coffee resistance to Colletotrichum kahawae is associated with lignification, accumulation of phenols and cell death at infection sites. Physiol. Mol. Plant Pathol. 77:23-32.

Maia, I., Horta, M., Cravador, A., and Medeira, C. 2012. Loss of aggressiveness of Phytophthora cinnamomi (beta-cinnamomin silenced strain) in the infection of Castanea sativa. Microsc. Microanal.: 17-18.

Martins, L., Castro, J., Macedo, W., Marques, C., and Abreu, C. 2007. Assessment of the spread of chestnut ink disease using remote sensing and geostatistical methods. Eur. J. Plant Pathol. 119:159-164.

Mellersh, D. G., and Heath, M. C. 2003. An investigation into the involvement of defense signaling pathways in components of the nonhost resistance of Arabidopsis thaliana to rust fungi also reveals a model system for studying rust fungal compatibility. Mol. Plant-Microbe Interact. 16:398-404.

Milholland, R. D. 1975. Pathogenicity and histopathology of Phytophthora cinnamomi on highbush and rabbiteye blueberry. Phytopathology 65: 789-793.

Miranda-Fontaíña, M. E., Fernández-López, J., Vettraino, A. M., and Vannini, A. 2007. Resistance of Castanea clones to Phytophthora cinnamomi: Testing and genetic control. Silvae Genet. 56:11-21.

Münch, S., Lingner, U., Floss, D. S., Ludwig, N., Sauer, N., and Deising, H. B. 2008. The hemibiotrophic lifestyle of Colletotrichum species. J. Plant Physiol. 165:41-51.

Oßwald, W., Fleischmann, F., Rigling, D., Coelho, A. C., Cravador, A., Diez, J., Dalio, R. J., Horta Jung, M., Pfanz, H., Robin, C., Sipos, G., Solla, A., Cech, T., Chambery, A., Diamandis, S., Hansen, E., Jung, T., Orlikowski, L. B., Parke, J., Prospero, S., and Werres, S. 2014. Strategies of attack and defence in woody plant-Phytophthora interactions. For. Pathol. 44:169-190.

Phillips, D. 1987. Histological changes in the roots of an avocado cultivar, Duke 7, infected with Phytophthora cinnamomi. Phytopathology 77:691-698.

Pomar, F., Merino, F., and Barceló, A. R. 2002. O-4-linked coniferyl and sinapyl aldehydes in lignifying cell walls are the main targets of the Wiesner (phloroglucinol-HCl) reaction. Protoplasma 220:17-28.

Redondo, M. Á., Pérez-Sierra, A., Abad-Campos, P., Torres, L., Solla, A., Reig-Armiñana, J., and García-Breijo, F. 2015. Histology of Quercus ilex roots during infection by Phytophthora cinnamomi. Trees 29:1943-1957.

Robinson, L. H., and Cahill, D. M. 2003. Ecotypic variation in the response of Arabidopsis thaliana to Phytophthora cinnamomi. Australas. Plant Pathol. 32:53-64.

Rookes, J. E., Wright, M. L., and Cahill, D. M. 2008. Elucidation of defence responses and signalling pathways induced in Arabidopsis thaliana following challenge with Phytophthora cinnamomi. Physiol. Mol. Plant Pathol. 72:151-161

Ruiz Gómez, F. J., Navarro-Cerrillo, R. M., Sánchez-Cuesta, R., and Pérez-de-Luque, A. 2015. Histopathology of infection and colonization of Quercus ilex fine roots by Phytophthora cinnamomi. Plant Pathol. 64: 605-616.

Santos, C., Duarte, S., Tedesco, S., Fevereiro, P., and Costa, R. L. 2017a. Expression profiling of Castanea genes during resistant and susceptible interactions with the oomycete pathogen Phytophthora cinnamomi reveal possible mechanisms of immunity. Front. Plant Sci. 8:515. 
Santos, C., Machado, H., Correia, I., Gomes, F., Gomes-Laranjo, J., and Costa, R. 2015a. Phenotyping Castanea hybrids for Phytophthora cinnamomi resistance. Plant Pathol. 64:901-910.

Santos, C., Nelson, C. D., Zhebentyayeva, T., Machado, H., Gomes-Laranjo, J., and Costa, R. L. 2017b. First interspecific genetic linkage map for Castanea sativa $\times$ Castanea crenata revealed QTLs for resistance to Phytophthora cinnamomi. PLoS One 12:e0184381.

Santos, C., Zhebentyayeva, T., Serrazina, S., Nelson, C. D., and Costa, R. 2015b. Development and characterization of EST-SSR markers for mapping reaction to Phytophthora cinnamomi in Castanea spp. Sci. Hortic. (Amsterdam) 194:181-187.

Sena, K., Crocker, E., Vincelli, P., and Barton, C. 2018. Phytophthora cinnamomi as a driver of forest change: Implications for conservation and management. For. Ecol. Manage. 409:799-807.

Serrazina, S., Santos, C., Machado, H., Pesquita, C., Vicentini, R., Pais, M. S., and Costa, R. 2015. Castanea root transcriptome in response to Phytophthora cinnamomi challenge. Tree Genet. Genomes 11:6.

Silva, M. C., Nicole, M., Guerra-Guimarães, L., and Rodrigues, C. J. 2002. Hypersensitive cell death and post-haustorial defence responses arrest the orange rust (Hemileia vastatrix) growth in resistant coffee leaves. Physiol. Mol. Plant Pathol. 60:169-183.

Talhinhas, P., Mota-Capitão, C., Martins, S., Ramos, A. P., Neves-Martins, J. Guerra-Guimarães, L., Várzea, V., Silva, M. C., Sreenivasaprasad, S., and Oliveira, H. 2011. Epidemiology, histopathology and aetiology of olive anthracnose caused by Colletotrichum acutatum and C. gloeosporioides in Portugal. Plant Pathol. 60:483-495.

Underwood, W. 2012. The plant cell wall: A dynamic barrier against pathogen invasion. Front. Plant Sci. 3:85.

van den Berg, N., Christie, J. B., Aveling, T. A. S., and Engelbrecht, J. 2018. Callose and $\beta$-1,3-glucanase inhibit Phytophthora cinnamomi in a resistant avocado rootstock. Plant Pathol. 67:1150-1160.

Vannini, A., and Vettraino, A. M. 2001. Ink disease in chestnuts: Impact on the European chestnut. For. Snow Landsc. Res. 76:345-350.

Vleeshouwers, V. G. A. A., Van Dooijeweert, W., Govers, F., Kamoun, S., and Colon, L. T. 2000. The hypersensitive response is associated with host and nonhost resistance to Phytophthora infestans. Planta 210:853-864.

Zentmyer, G. A., and Mircetich, S. M. 1966. Saprophytism and persistence in soil by Phytophthora cinnamomi. Phytopathology 56:710-712. 